\title{
A DINÂMICA REGIONAL DA ECONOMIA DAS CHARQUEADAS E A PRÁTICA DO FUTEBOL NAS CIDADES DE PELOTAS E RIO GRANDE (RS)
}

\author{
Patrícia Volk Schatz ${ }^{1}$ \\ Carlos José Espíndola
}

Resumo: Este artigo visa identificar as relações entre a dinâmica regional da economia das charqueadas e o desenvolvimento da prática do futebol nas cidades de Pelotas e Rio Grande (RS). Pretende-se destacar a influência de países vizinhos, do capital industrial e da aristocracia no processo de formação de uma economia local e na própria difusão de práticas futebolísticas. Este esporte conheceu diferentes vias de introdução no Brasil que são explicadas, em parte, pelas relações econômicas estabelecidas com outros países. O Rio Grande do Sul apresenta algumas combinações que elucidam a disseminação pioneira do futebol, principalmente na região sul do estado. As cidades de Pelotas e Rio Grande formaram o maior polo econômico e demográfico da região sul do Brasil entre meados do século XIX e começo do XX, estabelecendo relações comerciais com os países do rio da Prata, atraindo imigrantes europeus e capital inglês. A cidade de Pelotas, localizada entre a Campanha gaúcha e o porto de Rio Grande, se tornou a capital da aristocracia do charque que financiou a emergência de novos espaços de sociabilidade como teatros, cafés e clubes. O futebol compreendido como uma prática europeia moderna é gradativamente incorporado pela elite pelotense. Neste mesmo sentido, é a economia do charque que torna o porto de Rio Grande no maior do Brasil meridional, atraindo investimentos estrangeiros nas atividades portuárias, fabris e em infraestrutura. A colônia inglesa da cidade se reunia em clubes e praticava o futebol, compartilhando-o também com os trabalhadores alemães. A atividade portuária em Rio Grande, as charqueadas na cidade de Pelotas e a influência platina são fatores que concorreram na formação dos primeiros clubes de futebol e ligas regionais no final do século XIX e início do XX. Assim, visando compreender as relações entre a dinâmica geográfica e histórica das cidades de Pelotas e Rio Grande com a dispersão do esporte bretão o texto recorrerá metodologicamente à revisão bibliográfica e documental.

Palavras-chave: Charque. Futebol. Pelotas. Rio Grande.

\section{THE REGIONAL DYNAMICS OF THE ECONOMY OF THE CHARQUEADAS AND THE PRACTICE OF FOOTBALL IN THE CITIES OF PELOTAS AND RIO GRANDE (RS)}

\begin{abstract}
This article aims to identify the relations between the regional dynamics of the charqueadas economy and the development of soccer practice in the cities of Pelotas and Rio Grande (RS). It is intended to highlight the influence of neighboring countries, industrial capital and aristocracy in the process of forming a local economy and the very diffusion of football practices. This sport has known different routes of introduction in Brazil that are explained, in part, by the economic relations established with other countries. Rio Grande do Sul presents some combinations that elucidate the pioneering spread of football, especially in the southern region of the state. The cities of Pelotas and Rio Grande formed the largest economic and demographic pole of southern Brazil between the mid-19th and early 20th centuries, establishing trade relations with the countries of the River Plate, attracting

\footnotetext{
${ }^{1}$ Doutoranda em Geografia, Universidade Federal de Santa Catarina (UFSC). Email: paty_schatz@yahoo.com.br 2 Pós-Doutor em Geografia, Professor de Geografia da Universidade Federal de Santa Catarina. Email: carlos.espindola@ufsc.br
} 
European immigrants and English capital. The city of Pelotas, located between the Camacho gaúcha and the port of Rio Grande, became the capital of the charque aristocracy that financed the emergence of new spaces of sociability such as theaters, cafes and clubs. Football understood as a modern European practice is gradually incorporated by the Pelotan elite. In this same sense, it is the charque economy that makes the Rio Grande port the largest in southern Brazil, attracting foreign investments in port activities, manufacturing and infrastructure. The English colony of the city met in clubs and practiced the football, sharing it also with the German workers. The port activity in Rio Grande, the charqueadas in the city of Pelotas and the platinum influence are factors that contributed to the formation of the first football clubs and regional leagues in the late nineteenth and early twentieth centuries. Thus, in order to understand the relations between the geographic and historical dynamics of the cities of Pelotas and Rio Grande with the dispersion of the sport of Breton, the text will resort methodologically to the bibliographical and documentary revision.

Keywords: Charque. Football. Pelotas. Rio Grande.

\section{LA DINÁMICA REGIONAL DE LA ECONOMÍA DE LAS CHARQUEADAS Y LA PRÁCTICA DEL FÚTBOL EN LAS CIUDADES DE PELOTAS Y RIO GRANDE (RS)}

Resumen: Este artículo pretende identificar las relaciones entre la dinámica regional de la economía de las charqueadas y el desarrollo de la práctica del fútbol en las ciudades de Pelotas y Rio Grande (RS). Se pretende destacar la influencia de países vecinos, del capital industrial y de la aristocracia en el proceso de formación de una economía local y en la propia difusión de prácticas futbolísticas. Este deporte conoció diferentes vías de introducción en Brasil que son explicadas, en parte, por las relaciones económicas establecidas con otros países. Río Grande do Sul presenta algunas combinaciones que elucidan la diseminación pionera del fútbol, principalmente en la región sur del estado. Las ciudades de Pelotas y Rio Grande formaron el mayor polo económico y demográfico de la región sur de Brasil entre mediados del siglo XIX y comienzos del XX, estableciendo relaciones comerciales con los países del río de la Plata, atrayendo inmigrantes europeos y capital inglés. La ciudad de Pelotas, ubicada entre la Campaña gaúcha y el puerto de Rio Grande, se convirtió en la capital de la aristocracia del charque que financió la emergencia de nuevos espacios de sociabilidad como teatros, cafés y clubes. El fútbol comprendido como una práctica europea moderna es gradualmente incorporado por la elite pelotense. En este mismo sentido, es la economía del charque que hace el puerto de Rio Grande en el más grande del Brasil meridional, atrayendo inversiones extranjeras en las actividades portuarias, fabriles y en infraestructura. La colonia inglesa de la ciudad se reunía en clubes y practicaba el fútbol, compartiéndolo también con los trabajadores alemanes. La actividad portuaria en Rio Grande, las charqueadas en la ciudad de Pelotas y la influencia platina, son factores que concurrieron en la formación de los primeros clubes de fútbol y ligas regionales a finales del siglo XIX y principios del XX. Así, visando comprender las relaciones entre la dinámica geográfica e histórica de las ciudades de Pelotas y Rio Grande con la dispersión del deporte bretón el texto recurrirá metodológicamente a la revisión bibliográfica y documental.

Palabras clave: Carne Seca. Fútbol. Pelotas. Rio Grande. 


\section{Introdução}

A identificação dos processos de introdução e dispersão das práticas esportivas no Brasil passa necessariamente pelo entendimento da dinâmica territorial e histórica das diferentes regiões.

Ao tratar-se do Rio Grande do Sul no século XIX e início do XX é preciso ressaltar a configuração territorial resultante de conflitos armados como a Guerra da Cisplatina (18251828), a Revolução Farroupilha (1835-1845) e Guerra do Paraguai (1864-1870); de dispositivos como a Lei de Terras, dos contingentes migratórios, das relações do estado riograndense-do-sul com os países do Rio da Prata, da produção do charque e do capital internacional. Essas condicionantes geográficas e históricas foram determinantes para a via platina de entrada do futebol no Brasil, um caso particular deste processo de adoção da prática. $^{3}$

Para compreender-se a dispersão do futebol pelo território brasileiro a partir de diferentes locais e por diversos agentes é importante considerar que as cidades situadas nas fronteiras na região do Prata puderam conhecer e adotar o esporte simultaneamente aos grandes centros nacionais como São Paulo e Rio de Janeiro. Esse quadro justifica-se pelas relações que as cidades do RS mantinham com as capitais Montevidéu e Buenos Aires, e, também, por conta da expansão das ferrovias dos países vizinhos até o Brasil. Este segundo fator explica relatos da prática do futebol nas cidades de Santana do Livramento e Uruguaiana antes do ano de 1900. (PRODANOV; FERNANDES, 2009)

Neste sentido, a respeito da fundação do Esporte Clube 14 de Julho da cidade de Santana do Livramento, Mascarenhas ressalta que

Considerando-se sua localização, distantes dos grandes centros urbanos nacionais, das zonas portuárias mais dinâmicas ou de outras atividades potencialmente aglutinadoras de agentes britânicos (minas, grandes fábricas, etc), Livramento estaria alijada do mapa do futebol no Brasil no início do século. Não fosse, é claro, a forte conexão com Montevidéu. (MASCARENHAS, 2001, p. 145)

Assim, as diversas relações econômicas, políticas e culturais entre o Brasil e países vizinhos, como a Argentina e o Uruguai, contribuem para se compreender uma das vias de introdução do futebol no país.

\footnotetext{
${ }^{3}$ Para o debate ver: MASCARENHAS, Gilmar. A bola nas redes e o enredo do lugar: uma geografia do futebol e seu advento no Rio Grande do Sul. Tese de Doutorado, Universidade de São Paulo, 2001.
} 
Deste modo, também é importante investigar como se deu o desenvolvimento da prática do esporte bretão em cidades como Pelotas e Rio Grande, consideradas polos econômicos e demográficos da região sul do Brasil entre os séculos XIX e XX.

Rio Grande, fundada em 1737, é a primeira povoação oficial da província do Rio Grande do Sul. Por conta da dinâmica econômica regional decorrente do charque o porto de Rio Grande se tornou o maior do Brasil meridional, só sendo superado em volume de movimentação pelo porto da capital Porto Alegre. Era forte a presença do capital inglês na cidade portuária, sendo que estes incentivaram a criação da Câmara do Comércio e os primeiros investimentos em infraestrutura. Em 1880 a cidade de Rio Grande era o principal centro industrial do RS com destaque para a fábrica de tecidos Rheingantz. A vida cultural era intensa, pois as companhias europeias de teatro, ballet e ópera incluíam Rio Grande em seu roteiro de apresentações entre Buenos Aires e Montevidéu.

Já a cidade de Pelotas, localizada entre a Campanha gaúcha e o porto de Rio Grande, foi fundada em 1812. Entre a segunda metade da década de 1850 e o final do século XIX quase todo gado do estado era abatido em Pelotas e a cidade se tornou a capital da aristocracia do charque. As abastadas famílias pelotenses passaram a deslocar suas residências das fazendas para o centro da cidade e os jovens da elite eram enviados à Europa para estudos. $\mathrm{O}$ capital acumulado com as charqueadas contribuiu para o processo de industrialização local e permitiu investimentos em infraestrutura como telégrafos, telefones, bondes e ferrovias. Ressalta-se também que emergiram novos espaços de sociabilidade como teatros, cafés e clubes.

Desta forma este artigo objetiva identificar a relação da dinâmica regional e econômica das charqueadas com o desenvolvimento da prática do futebol nas cidades de Pelotas e Rio Grande. O texto é dividido em duas partes além da introdução e conclusão, sendo a primeira sobre as condicionantes históricas e geográficas da dinâmica regional das cidades estudadas. O segundo item tratará principalmente da introdução e difusão do futebol nas cidades de Pelotas e Rio Grande. Metodologicamente se recorrerá à revisão bibliográfica e documental.

Formação territorial, conjuntura histórica e a economia do charque: as cidades de Pelotas e Rio Grande

Há uma ampla literatura que trata dos processos de formação do território riograndense-do-sul. Entre os trabalhos destacam-se Curtis (1964), Thomas (1976), Guazzelli (1998), Santos (2001), Maestri (2006; 2008), Osório (2007), Christillino (2010), entre outros. 
De forma geral este escopo de obras discute questões relacionadas ao povoamento, ocupação territorial e o papel desempenhado por estancieiros, lavradores e comerciantes na constituição do Rio Grande do Sul.

Para se tratar da formação do território sul-rio-grandense é importante recorrer à algumas considerações históricas relativas ao interesse econômico e geopolítico de Portugal e Espanha. O Tratado de Tordesilhas, do século XV, havia legado aos espanhóis o referido território, enquanto que Portugal mantinha largo interesse na região por conta do comércio e contrabando com as áreas mineradoras dos Andes.

A contínua permanência dos portugueses na região culminou na fundação da Colônia de Sacramento às margens do Rio da Prata em 1680 e, em resposta aos avanços de Portugal, na criação dos Sete Povos da Missões, entre 1682 e 1706, por jesuítas espanhóis. Esses povoamentos incentivaram o desenvolvimento da pecuária que, segundo Christillino (2010), culminou em incursões em terras sul-rio-grandenses a partir do século XVIII. Ainda de acordo com Christillino (2010) "a instalação das estâncias exigiu a formação de verdadeiras milícias em torno dos estancieiros. As milícias eram indispensáveis à defesa dessas unidades produtivas [...]” (CHRISTILLINO, 2010, p. 30)

Durante o século XVIII a economia praticada por tropeiros e estancieiros no território rio-grandense baseava-se nas exportações de gado e de muares. Além disso havia a extração de subprodutos como o couro, sebos e graxas. ${ }^{4}$ Segundo Pesavento

o tipo social da época deste período - o tropeiro - era necessariamente um chefe de um bando armado. Esta fase do tropeiro foi marcada pela abertura de vias de comunicação do Rio Grande do Sul com o restante do país (estrada do litoral, 1703; estrada da serra, 1727), ao longo das viagens dos tropeiros. (PESAVENTO, 1997, p. 14)

A criação de gado e o desenvolvimento infraestrutural contribuíram para a consolidação da economia do charque. Em 1780 houve o aumento do número de charqueadas no RS por conta da diminuição da produção no Nordeste brasileiro, sendo que esta economia rapidamente superou em valores as exportações de couros. Também destaca-se que as primeiras charqueadas surgiram para abastecer a demanda alimentar de populações de baixa renda e do crescente número de escravos africanos que chegavam à América portuguesa.

Para Vargas (2014) as charqueadas de Pelotas foram possibilitadas pelo investimento de comerciantes e o capital resultante desta economia era investido em atividades mercantis. A cidade atraiu, durante o fim do século XVIII e o XIX, expressivo número de comerciantes

\footnotetext{
${ }^{4}$ Segundo Maestri (2008) estes subprodutos eram vendidos na Europa, em Buenos Aires e em Montevidéu. O autor também destaca a prática de contrabando destes produtos.
} 
que investiram seus capitais em fábricas e na compra de escravos africanos. Para Christillino (2010) também é importante compreender que o rendimento proveniente do charque permitiu aos estancieiros acelerar o processo de apropriação de terras no Rio Grande do Sul no final do século XVIII e início do XIX.

Ressalta-se que havia no território sul-rio-grandense relações sociais e de propriedade pautadas por um lado nas ações de milícias que asseguravam rebanhos e estâncias e, por outro, em movimentos de resistência de grupos indígenas ao avanço dos europeus. O contínuo conflito pelas terras e a existência desta "fronteira móvel" inutilizava a política portuguesa de concessão de Sesmarias. A regulamentação da ocupação da terra dependia da atuação das milícias e grupos armados que foram fundamentais na demarcação dos limites fronteiriços.

No ano de 1801 uma milícia, organizada por um estancieiro e um miliciano, retomou a região dos Sete Povos das Missões e, em 1807, foi criada a Capitania de São Pedro do Rio Grande do Sul. Os avanços e recuos nas fronteiras visadas por espanhóis e portugueses culminou em uma situação particular sobre a propriedade da terra.

Muitos dos sul-rio-grandenses ou súditos do império português e, posteriormente, do Brasil formavam ou adquiriam estâncias na região platina, em muitos casos, situadas essas em território estrangeiro. Os proprietários não poderiam contar com as leis e chancelas portuguesas e, mais tarde, brasileiras, para a afirmação e segurança de suas estâncias. Os seus títulos de concessões e a "legitimidade" de suas ocupações poderiam ser contestadas pelas autoridades platinas. Nesse sentido, as articulações com as redes sociais e políticas estabelecidas no interior do Vice-reino do Prata eram fundamentais aos luso-brasileiros que possuíam fazendas nos dois lados da fronteira. (CHRISTILLINO, 2010, p. 35)

Além disso é preciso destacar que a ocupação da Cisplatina no início do século XIX por luso-brasileiros promoveu o aumento da criação de gado e, consequentemente, da produção do charque. Porém, os conflitos pela independência deste território entre os anos de 1825 e 1828 culminaram na assinatura do Tratado do Rio de Janeiro e na emancipação do Uruguai. $^{5}$

A determinação de novas fronteiras meridionais resultou na decadência das atividades de contrabando na região, no aumento do controle fiscal, em restrições para o deslocamento dos rebanhos e no aumento da competitividade entre criadores de gado do Brasil e do Uruguai. Além disso, houve o aumento das taxações sobre a produção de charque, de sebo, de

\footnotetext{
${ }^{5}$ Para Soares (2006) com o fim das guerras de independência houve o aumento da livre circulação na região do Prata e a intensificação do comércio sendo que "Buenos Aires e Montevidéu possibilitavam a entrada de produtos importados mais baratos para as províncias do sul do Brasil e do Mato Grosso através do comércio de livre transito" (SOARES, 2006, p. 47). Nesta conjuntura Soares (2006) ressalta exportação de produtos brasileiros como o fumo, aguardente, açúcar, café, erva-mate, madeira, farinha de mandioca e arroz.
} 
couro, de graxas e da erva-mate ${ }^{6}$. O descontentamento conferido por esta conjuntura da primeira metade do século XIX contribuiu para a deflagração da Revolução Farroupilha ${ }^{7}$.

Ainda acerca da produção de charque em Pelotas os dados de Vargas (2014) ressaltam que "se em 1822 havia 22 charqueadas na região, em 1850 este número atingiu a casa dos 30, em 1873 chegou aos 35, e em 1880, a 38. Os anos de 1860 são considerados o grande auge econômico do setor." (VARGAS, 2014, P. 541). Para Dalmazo (2004) ao longo do século XIX o charque e o couro representaram os principais produtos da pauta exportadora do RS, somando $70 \%$ dos valores negociados a partir do porto de Rio Grande. ${ }^{8}$

Já no início do século XIX o Nordeste, principalmente Pernambuco e Bahia, tornou-se o principal comprador de charque sul-rio-grandense. ${ }^{9}$ De acordo com Vargas (2014) as vendas de charque do RS entre 1837 e 1889 revelaram uma recuperação do setor pós Revolução Farroupilha (1835-1845) e Guerra Grande (1838-1851).

Ao longo de todo o século XIX, o charque foi o produto-rei da economia sulrio-grandense e permaneceu no topo das exportações provinciais. Concentrando milhares de cativos e abatendo milhões de reses, Pelotas destacou-se como grande complexo charqueador da região. Localizado no sudeste da província, há alguns quilômetros do porto marítimo de Rio Grande, o município é cortado por vias fluviais que favoreceram o escoamento da produção e propiciaram o e enriquecimento dos charqueadores locais. (VARGAS, 2011, p. 01)

Dada a conjuntura do estado sulista no século XIX infere-se que estanceiros da Campanha gaúcha, comerciantes de Porto Alegre e Rio Grande e, também, charqueadores de Pelotas representavam a elite social e econômica do RS. ${ }^{10}$

Contudo, de acordo com Vargas (2011), as fortunas e investimentos dos charqueadores eram maiores e mais diversificados em relação aos demais, sendo que

\footnotetext{
${ }^{6}$ De acordo com Christillino (2010) o charque produzido no RS e comercializado com o Sudeste era taxado em $25 \%$.

${ }^{7}$ Ver mais em: LEITMAN, Spencer. Raízes sócio-econômicas da Guerra dos Farrapos. Rio de Janeiro: Graal, 1979.

${ }^{8}$ No século XIX Pelotas, Montevidéu e Buenos Aires eram os principais produtores de charque da América do Sul. Além disso, se ressalta que Sluyter (2010) insere a cidade de Pelotas no tasajo trail. Esta seria uma rota mercantil que ligaria o Rio da Prata à Cuba e as atividades das charqueadas, do tráfico de escravos africanos e da produção de açúcar. A mão-de-obra cativa era explorada nas duas atividades econômicas e o charque era o alimento utilizado na alimentação dos mesmos. Para o debate ver: SLUYTER, Andrew. The Hispanic Atlantic's Tasajo Trail. Latin American Research Review, v. 45, n. 1, 2010, p. 98-120.

${ }^{9}$ Segundo Vargas (2014) o RS, em 1787, que comercializava charque apenas com o Rio de Janeiro, vendeu 117 mil arrobas. Para o mercado nordestino as vendas passaram de 400 mil arrobas em 1793, de 500 mil arrobas em 1797 e de 820 mil arrobas de média ano na década de 1800. Osório (2007) ressalta que a Bahia tornou-se no início do século XIX no maior comprador de charque do RS, mas que o RJ superou o estado nordestino na compra do produto em 1820 . O autor também ressalta que ao final da década de 1810 Havana importava $13 \%$ da produção rio-grandense-do-sul.

${ }^{10}$ Para mais informações sobre os fluxos do comércio de charque no século XIX ver Beruti (2011) e Silveira (2006)
} 
aplicavam capital em armazéns, embarcações, ações, dívidas ativas, fazendas, imóveis e cativos africanos. Ainda para o autor é importante ressaltar o auge do abate e exportações de charque entre os anos de 1850 e 1860, bem como compreender que "este período também foi marcado pela alta do preço dos cativos e uma crescente concentração dos mesmos nas mãos de poucos charqueadores, a perda do mercado consumidor do sudeste para os saladeros platinos e uma baixa dos preços do charque". (VARGAS, 2011, p. 02)

De acordo com Monastério (2005) a população de Pelotas aumentou em 754\% entre 1814 e 1860, totalizando 13 mil habitantes ${ }^{11}$. Contudo, verifica-se na segunda metade do século XIX a diminuição do número de charqueadas pelotenses. Se haviam 32 estabelecimentos em 1880, esse total diminuiu para 21 no ano de 1887 e para 11 charqueadas em 1900. (VARGAS, 2011)

Sendo assim, identificam-se a partir do século XIX novas transformações econômicas no RS com a queda da produção do charque e o aumento da produção agrícola oriunda de propriedades, sobretudo, de imigrantes alemães e italianos ${ }^{12}$.

Contudo, a produção e comercialização do charque representou a principal atividade econômica da porção sul do RS entre o século XVIII e parte do XIX. As considerações sobre a formação histórica e a geográfica do Rio Grande do Sul, bem como os apontamentos sobre o desenvolvimento econômico das cidades de Pelotas e Rio Grande contribuem para a compreensão das relações socioculturais forjadas entre o final do século XIX e início do XX.

\section{O desenvolvimento do futebol nas cidades de Pelotas e Rio Grande (RS)}

A introdução do futebol no Rio Grande do Sul ocorre na zona sul do estado através da pujança das charqueadas, da influência platina e do desenvolvimento industrial. Ressalta-se que as atividades esportivas desenvolveram-se conforme o crescimento econômico e mudanças socioculturais de fins do século XIX e início do XX.

As relações comerciais entre o Brasil e países vizinhos como Uruguai e Argentina davam-se, entre outros, através do importante porto de Rio Grande, por onde eram escoadas os produtos das charqueadas platinas. Nesse sentido, a presença do capital inglês, justificado

\footnotetext{
${ }^{11}$ Segundo Assumpção (1995) no ano de 1814 a população de Pelotas era de 2.419 habitantes, a de Rio Grande era de 3.590 pessoas, a de Porto Alegre contava com 6.111, as Missões totalizavam 7.951 habitantes. A província somava 70.656 pessoas.

${ }^{12}$ Pesavento (1997) ressalta a importância dos fluxos migratórios de alemães a partir de 1824 e de italianos após 1875. Para a autora já a partir da década de 1840 verifica-se que as propriedades agrícolas destes imigrantes passaram a destacar-se no abastecimento do mercado interno nacional. Dentre os produtos destacam-se o vinho, a farinha de mandioca, o trigo, a cerveja, o fumo e a banha.
} 
pela relação comercial com o porto, incentivou a criação da Câmara do Comércio de Rio Grande e investimentos em infraestrutura.

Já em 1880 a cidade de Rio Grande era um dos principais centros industriais do estado com destaque para a fábrica de tecidos Rheingantz, também chamada de União Fabril ${ }^{13}$. De acordo com Ferreira (2013) a fábrica, que foi uma das maiores do setor têxtil do sul do Brasil no século XIX, permitiu o avanço

em processos de urbanização com a introdução de sistemas de transporte urbano, tais como o bonde, a implantação de serviços públicos no bairro Cidade Nova, reduto da população imigrante e operária e a dinamização de setores como o ferroviário e o portuário, tendo em vista o fluxo de produção e de matérias-primas. (FERREIRA, 2013, p. 70)

Este dinamismo econômico e as transformações promovidas no espaço urbano também refletiam na vida cultural da cidade portuária que passou a receber companhias europeias de teatro, de ballet e de ópera que incluíam Rio Grande em seus roteiros entre as capitais uruguaia e argentina. Nesse sentido, Rigo (2013) ressalta a importância do porto de Rio Grande como um centro de trocas econômicas e socioculturais já que os navios aportavam trazendo "bolas de futebol, uniformes, estatutos de clubes esportivos, regramentos impressos do futebol e jornais europeus que comentavam e incentivavam a prática do novo esporte" (RIGO, 2013, p. 41).

No início do século XX foi fundado o Sport Club Rio Grande pela iniciativa dos alemães Johannes Cristian Moritz Minnermann e Richard Völkers, ambos trabalhadores da importadora inglesa Thomsen \& Cia. Para Rigo (2013), apesar da importância das trajetórias individuais de agentes como Minnermann na difusão do futebol é a condição de Rio Grande como cidade portuária que propiciou condições para o desenvolvimento desta prática esportiva.

É a partir de uma nova dinâmica sociocultural proporcionada pela economia do charque e, também, pela criação pioneira do Sport Club Rio Grande que o futebol difundiu-se para outras cidades sul-rio-grandenses. Sobre o desenvolvimento de novas atividades em Pelotas Mascarenhas destaca que

A classe senhorial pelotense, oriunda da rústica atividade saladeiril, uma vez enriquecida e instalada na cidade, adquire hábitos refinados, envia seus filhos a estudar na Europa e promove a modernização urbana dos marcos de

\footnotetext{
${ }^{13}$ Segundo Ferreira (2013) o alemão Carlos Guilherme Rheingantz em parceria com o sogro Miguel Tito de Sá e com o empresário alemão Hermann Vater fundaram a Fábrica Nacional de Tecidos e Panos de Rheingantz \& Vater no ano de 1873 como uma sociedade comanditária. A fábrica entrou em funcionamento no ano de 1874 processando lã oriunda de propriedades localizadas nas regiões de Livramento, Bagé, Uruguaiana e Santa Vitória do Palmar. (FERREIRA, 2013)
} 
influência parisiense: cafés, teatros e parques ajardinados começam a redesenhar o antes acanhado espaço público e a modificar atividades cotidianas na direção de uma sociabilidade burguesa. (MASCARENHAS, 2001, p. 145)

Em 1901 é organizada uma exposição de materiais esportivos em Pelotas com artigos provenientes do clube de Rio Grande, o que contribuiu para a divulgação do esporte. Nesse sentido, Rasch (2013) destaca que a excursão promovida pelo Sport Club Rio Grande na cidade de Pelotas não incentivou a imediata fundação de clubes, mas que foi importante para estimular a prática já que "[...] a rica cidade dispunha de uma elite com tempo para práticas de lazer e cultura, a ânsia pela modernidade e pela imitação do estilo de vida europeu" (RASCH, 2013, p. 14)

Anterior à excursão do Sport Club Rio Grande verifica-se que Pelotas já desenvolvia novos interesses por práticas culturais variadas a partir das elites locais. Houveram investimentos em espaços de sociabilidade como cafés, lojas, teatros, clubes esportivos, entre outros. A exemplo, no ano 1883 foi criado o Parque Pelotense, um espaço de encontro das elites locais em que eram desenvolvidas atividades diversas. Além disso, esta elite pelotense também impulsionou o processo de industrialização e investimentos diversos em infraestrutura como bondes, telégrafos, ferrovias e sistema de comunicação.

Com espaços mais apropriados para a prática do futebol e com o crescente interesse das elites pelotenses pelo esporte houve a criação do Athlético Foot-Ball Club no ano de 1904. Este feito foi possibilitado pela iniciativa de Otávio Mascarenhas que transferiu materiais esportivos de Montevidéu para o Brasil ${ }^{14}$. Neste mesmo ano, em Rio Grande, a Intendência Municipal concedeu ao clube local um terreno para a construção do estádio das Oliveiras.

Já em 1906 foram fundados em Pelotas os clubes C.S Internacional e Foot-Ball Clube, ambos de perfil elitista, que fundiram-se no ano de 1908 formando o Sport Club Pelotas. Esta fusão de clubes previu formar uma agremiação competitiva que representasse a cidade de Pelotas nos campeonatos disputados contra as equipes de Rio Grande e Porto Alegre ${ }^{15}$. A

\footnotetext{
${ }^{14}$ Rasch (2013) destaca que no ano de 1903 houve uma segunda excursão do Sport Club Rio Grande na cidade de Pelotas. Para o autor a fundação do Athlético Foot-Ball Club mostra a importância da via platina de introdução do futebol, pois foi a partir de materiais oriundos de Montevidéu que organizou-se o primeiro clube de Pelotas.

15 Ainda no ano de 1906 houve uma terceira excursão do Sport Club Rio Grande na cidade de Pelotas quando houve a realização de uma partida deste contra o C.S Internacional. Também é importante ressaltar a criação, em 1907, da Liga Pelotense de Foot-Ball que organizou e promoveu o campeonato estadual no ano de 1908. Apenas as ligas de São Paulo, Rio de Janeiro e Salvador eram anteriores. O campeonato de 1908 não obteve sucesso e só foi retomado a partir de 1913. Ressalta-se que neste período sem a realização de um campeonato regional os
} 
literatura e a imprensa esportiva comumente ressaltam a origem elitizada do Sport Club Pelotas atrelada aos charqueadores que

[...] ocupavam-se dessa atividade durante os primeiros quatro meses do ano - a época da safra- e, durante o restante do tempo, costumavam viajar pelo Rio de Janeiro e Europa. Voltavam com hábitos refinados, vestindo a rigor, fazendo pose, fundando e frequentando salões- fazendo uma fama que permanece até hoje. Era essa gente que tinha fundado o Sport Club Pelotas, de cores azul e amarelo, em 1908. Embora existissem ou passassem a existir outros times- Rio Branco, Ideal, Bancário, Guarani e, ainda, o Nono Regimento de Infantaria, que mais tarde mudou o nome para Farroupilha [...]. (PLACAR, 1977, p. 50)

Assim, destaca-se a origem elitizada do Sport Club Pelotas e a indisposição destes em divulgar ou praticar o esporte com outros grupos sociais ${ }^{16}$. Para tanto, os principais clubes de Pelotas criaram a primeira liga de futebol do estado com “[...] um conjunto de medidas cautelosas que se propunham a instrumentalizar o futebol, tornando-o uma prática cultural específica de uma classe social, um costume que deveria ser restrito a poucos”. (RIGO, 2004, p. 70-71)

Com a consolidação dos clubes pelotenses e a construção do estádio do S.C Pelotas alguns autores, entre estes Mascarenhas (2001), passam a destacar que o esporte torna-se um instrumento para divulgação de interesses comerciais. No ano de 1911 a Seleção do Uruguai é recebida em Pelotas para uma série de atividades recreativas, entre as quais "visitas a fábricas e charqueadas, podendo evidentemente estar envolvida uma estratégia de promoção/divulgação (e quiçá acordos comerciais) dos produtos pelotenses." (MASCARENHAS, 2001, p. 176)

Também é importante destacar que nas primeiras décadas do século XX identifica-se um processo crescente de mercantilização do futebol quando o esporte passa a ser oferecido como espetáculo nos estádios. Nesse sentido, Mascarenhas (2001) destaca o gradativo aumento de investimento em equipamentos esportivos, principalmente campos de futebol, por conta do notável ganho das bilheterias do S.C Pelotas.

clubes de Pelotas disputaram jogos amistosos com equipes de Bagé, Rio Grande e, também, com clubes uruguaios.

${ }^{16}$ Nesse sentido, Rasch (2013) ressalta que através da Liga Pelotense de Foot-Ball os clubes elitistas buscavam manter-se dissociados de clubes populares. No ano de 1908 o C.S Internacional negou pedido do Sport Club Esperança para a realização de um amistoso alegando que o clube pedinte não estava filiado à Liga Pelotense de Foot-Ball. 
Do mesmo modo, em Pelotas, o desenvolvimento fabril foi acompanhado da popularização do futebol com a criação, entre outros, do Grêmio Sportivo Brasil em $1911^{17}$. A revista Placar em artigo de setembro de 1977 e intitulado como "O Brasil é feito por eles" ressalta que "A história foi assim: operários que realizavam obras num campo de futebol foram maltratados pelo capataz. Deram as costas, partiram para os campos de várzea. E só voltaram pra anunciar: estava fundado o Grêmio Esportivo Brasil.” (PLACAR, 1977, p. 48)

Assim, Grêmio Sportivo Brasil e Sport Club Pelotas tornaram-se, além de principais rivais no futebol pelotense, representantes das mudanças históricas e socioculturais de fins do século XIX e começo do XX. Enquanto o Sport Club Pelotas foi fundado pela elite do charque, o Grêmio Sportivo Brasil nasceu de uma dissidência de operários da Cervejaria Haertel.

De forma geral verificou-se que nas cidades de Rio Grande e Pelotas houve a emergência de clubes ligados tanto às elite locais como também aos trabalhadores industriais. De modo geral o desenvolvimento econômico regional pautado na produção do charque e no parque industrial criou um ambiente as condições para a introdução e dispersão da prática do futebol.

\section{Considerações Finais}

O entendimento sobre a dinâmica regional das charqueadas nas cidades de Pelotas e Rio Grande (RS), entre os séculos XIX e XX, é de suma importância para a compreensão das diversas relações sociais e culturais estabelecidas no período. Este artigo pretendeu mostrar que a economia das charqueadas criou um ambiente propício para o desenvolvimento, entre outros, de práticas futebolísticas.

Ressaltou-se a importância da influência de países vizinhos no intercâmbio cultural que permitiu que o futebol, já praticado anteriormente naqueles países, fosse adotado no Brasil. E estas trocas culturais foram possíveis através das relações econômicas, da presença do capital inglês interessado nos negócios via Rio da Prata e da pujança das charqueadas. Como afirma Mascarenhas “[...] era o RS de então parte indissociável da realidade geográfica platina, e não algo externo com o que se estabelece relações." (MASCARENHAS, 2000, p. 02)

17 O Grêmio Sportivo Brasil foi criado no ano de 1911 por operários da Cervejaria Haertel, empresa de proprietários alemães 
Também destacou-se a importância das cidades de Pelotas e Rio Grande para a economia do RS nos séculos XVIII e XIX. Rio Grande, a primeira povoação da província sulrio-grandense, ganhou relevância como cidade portuária em que eram escoadas produtos das charqueadas platinas. O desenvolvimento de Rio Grande contou com investimentos em infraestrutura e em um parque industrial. Além disso, ressaltou-se que a cidade portuária recebia companhias europeias de teatro, ballet e ópera. Estas condições corroboram para a hipótese de que a economia regional do charque e as trocas culturais realizadas entre Brasil e países próximos foi fundamental para a difusão de novas práticas corporais e esportivas.

No caso de Pelotas, cidade fundada em 1812, destacou-se a consolidação desta como capital da aristocracia do charque. Os dados mostraram que entre a segunda metade da década de 1850 e o final do século XIX quase todo gado do RS era abatido na cidade de Pelotas. O capital acumulado com a economia do charque foi fundamental para os investimentos em infraestrutura urbana e também para o processo de industrialização local. Do mesmo modo que ocorreu em Rio Grande, emergiram na cidade das charqueadas espaços de sociabilidade como clubes recreativos, cafés e teatros.

O ambiente de efervescência cultural formado a partir do intercâmbio de experiências entre o RS e os países vizinhos, os investimentos em equipamentos de lazer como clubes, parques e estádios e, a formação dos primeiros clubes de futebol incentivaram a divulgação da prática futebolística para diversas cidades sul-rio-grandenses.

Nesse sentido, considera-se o período entre a segunda metade do século XIX e a década de 1920 como de prosperidade do futebol. Dentre diversos exemplos, ressaltou-se o caso do Grêmio Sportivo Brasil da cidade de Pelotas que somou uma série de títulos como os campeonatos locais de 1917, 1918 e 1919. Neste mesmo ano o clube pelotense venceu o primeiro Campeonato Gaúcho e participou também de um torneio no Rio de Janeiro.

Já a partir dos anos de 1920 identifica-se que a cidade de Bagé tornou-se a nova capital das charqueadas ${ }^{18}$, passando também a destacar-se no futebol sul-rio-grandense. Enquanto isso, Rio Grande e Pelotas deixaram de sobressair-se tanto na economia como no esporte.

\footnotetext{
${ }^{18}$ De acordo com Soares (2006) a cidade de Bagé passou a absorver o gado antes abatido em Pelotas ou no Uruguai, sendo que surgiram charqueadas na fronteira oeste, sobretudo, nas cidades de Itaqui, Quarai, Uruguaiana e Livramento.
} 


\section{Referências Bibliográficas}

ASSUMPÇÃO, Jorge Euzébio. Pelotas: escravidão e charqueadas (1780-1888). Dissertação de Mestrado em História do Brasil, PUC, POA, 1995.

BERUTE, Gabriel Santos. Atividades mercantis do Rio Grande de São Pedro: negócios, mercadorias e agentes mercantis (1808-1850). 2011. Tese (Doutorado) - PPG-História da UFRGS, Rio Grande do Sul, 2011.

CURTIS, M.L.L. Povoamento do Rio Grande do Sul. Porto Alegre: Instituto Gaúcho de Reforma Agrária, 1964.

DALMAZO, Renato A. As relações de comércio do Rio Grande do Sul - do século XIX a 1930. Porto Alegre: FEE, 2004.

FERREIRA, Maria Leticia Mazzucchi. Os fios da memória: fábrica Rheingantz entre passado, presente e patrimônio. Horizontes Antropológicos, Porto Alegre, v. 39, p.69-98, jan./jun.

2013.

GUAZZELli, César Augusto. O Horizonte da Província: a República Rio-grandense e os caudilhos do Rio da Prata (1835-1845). Tese de doutorado em História. Rio de Janeiro: PPGH-UFRJ, 1998.

LEITMAN, Spencer. Raízes sócio-econômicas da Guerra dos Farrapos. Rio de Janeiro: Graal, 1979.

MAESTRI, Mário. Uma história do Rio Grande do Sul: a ocupação do território. Passo Fundo: UPF Editora, 2006.

. O cativo, o gaúcho e o peão: considerações sobre a fazenda pastoril rio-grandense (1680-1964). MAESTRI, Mário (Org.). O negro e o gaúcho: estâncias e fazendas no Rio Grande do Sul, Uruguai e Brasil. Passo Fundo: UPF Editora, 2008, pp. 169-271.

MASCARENHAS, Gilmar. A bola nas redes e o enredo do lugar: uma geografia do futebol e seu advento no Rio Grande do Sul. Tese de Doutorado, Universidade de São Paulo, 2001.

. A via platina de introdução do futebol no Rio Grande do Sul. Lecturas:

Educación Física y Deportes. Revista Digital. Buenos Aires, Ano 5, n. 26, out. 2000.

Entradas e bandeiras: a conquista do Brasil pelo futebol. Rio de Janeiro: EdUERJ,

2014.MONASTÉRIO, Leonardo M. FHC errou? A economia da escravidão no Brasil meridional. In: História e Economia Revista Interdisciplinar da Brazilian Business School. São Paulo: Terra Comunicação Editorial, v.1, n. 1, 2005, p. 13-28.

NEVES, Hugo Alberto Pereira. Importância do porto do Rio Grande na economia do Rio Grande do Sul (1890-1930).1980. 210 f. Dissertação (Mestrado) - Curso de Curso de Pósgraduação em História do Brasil, Universidade Federal do Paraná, Curitiba, 1980.

OSÓRIO, Helen. O império português no sul da América: estancieiros, lavradores e comerciante. Porto Alegre: Editora da UFRGS, 2007.

PESAVENTO, S. J. História do Rio Grande do Sul. $8^{\text {a }}$ ed. Porto Alegre: Mercado Aberto, 1997.

PRODANOV, Cleber Cristiano; FERNANDES, Luiz Fernando Framil. O futebol no Rio Grande do Sul e sua identidade: dos portos e fronteiras para as regiões coloniais. In: Simpósio Nacional de História, Fortaleza: ANPUH, 2009.

RASCH, Rafael Androli. O nosso sangue, a nossa raça: história, memória e identidade "xavantes" (estudo de caso da partida G.E. Brasil x C.R. Flamengo, taça de ouro 1985). Trabalho de Conclusão de Curso, Universidade Federal do Rio Grande do Sul, Instituto de Filosofia e Ciências Humanas, Universidade Federal do Rio Grande do Sul, Porto Alegre, 2013.

REVISTA PLACAR. São Paulo: Editora Abril, v. 386, 16 set. 1977. Semanal.

RIGO, L.C. Memórias de um futebol de fronteiras. Pelotas: Editora da Universidade Federal de Pelotas, 2004. 
. O Porto e a Fronteira: Notas sobre o Pioneirismo do Futebol no Interior Gaúcho. In: GOELLNER, Silvana Vilodre; VON MÜHLEN, Johanna Coelho (Org.). Memórias do Esporte e do Lazer no Rio Grande do Sul. Porto Alegre: Evangraf, 2013. p. 39-52.

SANTOS, Júlio Ricardo Quevedo (Org.). Rio Grande de São Pedro: povoamento e conquista. 2 ed. Porto Alegre: Martins Livreiro Editor, 2001.

SANTOS, E. de O. Agroturismo e turismo rural: alternativa econômica para a Metade Sul do Estado do Rio Grande do Sul. Santa Maria/RS: Ed. Facos, 2005.

SILVEIRA, Josiane Alves da. Rio Grande: portas abertas para as importações de sal no século XIX. 2006. Monografia (Trabalho de conclusão do curso) - Universidade Federal do Rio Grande, Rio Grande, 2006.

SLUYTER, Andrew. The Hispanic Atlantic's Tasajo Trail. Latin American Research Review, v. 45, n. 1, 2010, p. 98-120.

SMITH, Herbert. Do Rio de Janeiro à Cuyabá. Notas de um naturalista. São Paulo: Melhoramentos, 1922.

SOARES, Fernanda C. Santa Thereza: um estudo sobre as charqueadas da fronteira BrasilUruguai. 2006. 118 f. Dissertação (Mestrado) - Curso de Integração Latino Americana, Centro de Ciências Sociais e Humanas, Universidade Federal de Santa Maria, Santa Maria, 2006.

THOMAS, C. Conquista e povoamento do Rio Grande do Sul. Boletim Geográfico do Rio Grande do Sul, Porto Alegre, v.19, p. 17-27, 1976.VARGAS, Jonas Moreira. Os charqueadores de Pelotas, suas estratégias familiares e a transmissão de patrimônio (18301890). In: XXVI SIMPÓSIO NACIONAL DE HISTÓRIA, 25, 2011, São Paulo. Anais..... São Paulo: Anpuh, 2011. p. 1 - 17.

Abastecendo plantations: A inserção do charque fabricado em Pelotas (RS) no comércio atlântico das carnes e a sua concorrência com os produtores platinos (século XIX). História (São Paulo), [s.1.], v. 33, n. 2, p.540-566, dez. 2014. FapUNIFESP (SciELO). http://dx.doi.org/10.1590/1980-436920140002000025

Recebido em 10 de setembro de 2018. Aceito em 15 de outubro de 2018. 